DOI 10.14746/ppuam.2019.9.07

Matgorzata Polkowska ${ }^{1}$

\title{
Global Space Security and Counter-space Capabilities: the Legal and Political Challenges
}

\section{Introduction}

The growing use and reliance on space for national security has also led more states to examine and develop their own counter-space capabilities. Counter-space, also known as space control, is the set of capabilities or techniques that are used to gain space superiority. Space superiority is the ability to use space for one`s own purposes while denying it to an adversary. Accordingly, counter-space capabilities have both offensive and defensive elements that are supported by Space Situational Awareness (information about the space environment). Defensive counter-space helps protect one`s space assets from attack, while offensive counter-space tries to prevent the adversary from using their space asset. Anti-satellite weapons (ASAT) are a subset of offensive counter-space capabilities, although the satellite itself is only one part of the system that can be attacked. Offensive capabilities can be used to deceive, disrupt, deny, degrade, or destroy any of the three elements of a space system: the satellite, the ground system, or the communication links between them.

There are several different categories of offensive counter-space capabilities: a) direct ascent (weapons that use ground-, air-, or sea-launched missiles with interceptors that are used kinetically to destroy satellites through force of impact, but are not placed into orbit themselves; b) co-orbital (weapons that are placed into orbit and then maneuver to approach the target; c) directed energy (weapons that use focused energy, such as laser, particle, or microwave beams to interfere or destroy a space system; d) electronic warfare (weapons that use radiofrequency energy to interfere with or jam the communication to or from satellites; e) cyber (weapons that use software and network techniques, to compromise, control, interfere with, or destroy computer systems). ${ }^{2}$

1 Publication financed under the project implemented in the RESEARCH GRANT Program of the Ministry of National Defense Republic of Poland.

2 B. Weeden, V. Samson ed., Global Counterspace Capabilities: An Open Source Assessment, 2019, p. XV. T. Harrison, K. Johnson, T. G. Roberts, M. Bergethon, A. Coultrup, Space Threat Assess- 


\section{International Regulations on Space Security}

Space security legislation is very important for the international community, but also challenging. In 2008, Russia and China proposed a discussion on the project of the Treaty on the Prevention of the Placement of Weapons in Outer Space, the Threat of Use of Force against Outer Objects (PPWT) ${ }^{3}$ in the Conference of Disarmament in 2008. In 2014 a new Chinese-Russian treaty proposal would ban the placement of weapons in outer space but does not address weapons based on the ground that could destroy satellites. This is the first redraft of the PPWT presented for review since the original was presented. That document was rejected by many states (including the US) for a variety of reasons, including the grounds that it was unverifiable.

When they introduced the 2014 draft treaty, China and Russia offered an explanatory note. "We consider a legally binding ban on placement of weapons in outer space as one of the most important instruments of strengthening global stability and equal and indivisible security for all," it stated. However, there are several gaps that the PPWT does not address even in its latest $\mathrm{draft}^{4}$. Long discussion and criticism on the project have been presented in this matter by the US. For example, the PPWT had not succeeded in receiving large-scale endorsement principally on the fact that the draft treaty did not address direct-ascent Anti-Satellite (ASAT) systems nor did it address soft-kill weapons such as lasers that could be employed to permanently or temporarily disable a satellite. ${ }^{5}$ Moreover, the draft failed to address so-called "breakout" weapons, which could take the form of direct-ascent or co-orbital weapons that could be manufactured and launched in the event of hostilities. All these are inherently destabilizing and bear consideration yet remain unmentioned. Rather, the draft treaty emphasized a great deal on the placement of weapons in outer space, which would likely come in the form of co-orbital ASAT's, but overlooks the more dangerous aspect of ground-based assets targeting outer space assets as demonstrated with the Chinese ASAT test in 2007 that targeted the defunct FY-1C weather satellite. Even though that test brought down one of China's old weather satellites, the potential for intentional or unintentional incidents in the future is still

ment, 2019, pp. 3-5.

3 <www.unog.ch>.

4 Note verbal dated 2 August 2018 from the Delegation of the United States of America to the Conference on Disarmament addressed to the Secretary-General of the Conference transmitting the United States response to CD/2042 14 September 2015 titled "Letter dated 11 September 2015 from the Permanent Representative of the People's Republic of China to the Conference on Disarmament and the Chargé d'affaires a.i. of the Russian Federation regarding the United States of America analysis of the 2014 updated Russian and Chinese texts of the draft treaty on prevention of the placement of weapons in outer space and of the threat or use of force against outer space objects (PPWT)"

5 The draft treaty emphasizes a great deal on the placement of weapons in outer space, which would likely come in the form of co-orbital ASATs, but overlooks the more dangerous aspect of groundbased assets targeting outer space assets as demonstrated with the Chinese ASAT test in 2007. 
high and such capabilities raise the potential for dangerous consequences. Moreover, after recent revelations by the US Defense and State Departments that China has performed several disguised ASAT tests, it is clear that China has no intention of placing these weapon systems into the coverage of the PPWT ${ }^{6}$.

The draft treaty did not address the major issue presented by space debris, which confronts the long-term sustainability of outer space, especially in low Earth orbit. The issue of space debris is not mentioned anywhere in the proposed draft treaty, even though the issue poses a far bigger challenge than the placement of weapons in outer space. The potential for any state placing weapons, including weapons of mass destruction (WMDs), is highly remote, but the growth of the space debris population has already affected the functioning of outer space assets. This issue is important by the continued threat posed by the destructive capacity of hard-kill, direct-ascent ASATs. The PPWT should acknowledge the importance surrounding the creation of space debris by direct-ascent ASATs, but the current draft conveniently neglects to mention it. ${ }^{7}$

Ancillary to the issue of space debris creation is space debris removal. Technology designed to remediate space debris could also be used to interfere with functioning satellites belonging to another state. This so-called 'dual-use technology' is already a political issue that needs to be overcome in order for effective remediation to begin. However, the PPWT would complicate the issue because it gives additional legal leverage to a State Party that seeks to protest activities of another to remediate space debris by claiming that they can be "space weapon." Whether such a claim is a legitimate concern or a geopolitical maneuver on the part of the complaining State Party, it will surely complicate the issue of space debris remediation. That the PPWT does not mention this concern is troubling and further degrades its legitimacy.

Some of the definitional attempts in the current draft of the PPWT pose challenges. For example, the way which "use of force" or "threat of force" is defined raises questions about the intentions of states that might become signatories of PPWT in the future. There is also an issue about the differentiation that the draft treaty makes between States Parties and non-States Parties. Article II of the proposed treaty states, that States Parties to this Treaty shall "not resort to the threat or use of force against outer space objects of States Parties." However, it makes no prohibition against the outer space objects belonging to non-State

\footnotetext{
6 J. Foust, U.S. Dismisses Space Weapons Treaty Proposal As "Fundamentally Flawed", "Space News" September 11, 2014.

7 CD/2129 Conference on Disarmament, 16 August 2018 GE.18-13568(E); Remarks of Richard H. Buenneke Senior Advisor, National Security Space Policy Office of Emerging Security Challenges Bureau of Arms Control, Verification and Compliance U.S. Department of State Panel on "Balancing national security and economic security in a contested and congested space domain"; "Greater Security Through International Space Collaboration" Seminar George Washington University Space Policy Institute The Aerospace Corporation's Center for Space Policy \& Strategy, July 19, 2018
} 
parties. This suggests that if the PPWT becomes binding international law, it will override customary norms of non-interference and leave the space objects of non-parties open to interference, unless they become a party to the treaty.

Additionally, the definition of "outer space object" used by the PPWT is considered by the US as not necessary and confusing, given that the Liability Convention $1972^{8}$ and the Rescue Agreement $1975^{9}$ have a working definition of "space object."That definition is already internationally accepted and even used in some domestic space law and would serve to integrate the PPWT into the current body of international space law. Having this new term defeats the purpose of trying to harmonize the PPWT with the existing international legal framework, which China and Russia are parties to, and suggests that the two countries seek to differentiate the PPWT from the existing body of international space law instead of integrating it.

Another inconsistency deals with the PPWT's reference to the self-defense provision in Article 51 of the UN Charter. China has objected in strong terms to the reference of Article 51 of the UN Charter - the right to individual or collective self-defense-in the International Code of Conduct ( $\mathrm{ICoC})$. However, this element is even further clarified in the text of the current draft treaty. The text of the 2008 draft states, "nothing in this Treaty may be interpreted as impeding the exercise by the States Parties of their right of self-defense in accordance with Article 51 of the Charter of the United Nations." The text in the current draft treaty takes a step further and adds a reference to collective self-defense in that "this Treaty shall by no means affect the States Parties' inherent right to individual or collective self-defense, as recognized by Article 51 of the UN Charter ${ }^{10}$."This inconsistency between railing against the "self-defense" principle of Article $51{ }^{11}$ mentioned in $\mathrm{ICoC}$ and promoting it within the PPWT brings into question the legitimacy for bringing the current draft forward to coincide with negotiations for the ICoC. ${ }^{12}$

8 Convention on International Liability for Damage Caused by Space Objects of 1972.

9 The Agreement on the Rescue of Astronauts, the Return of Astronauts and the Return of Objects Launched into Outer Space of 1975.

10 Nothing in the present Charter shall impair the inherent right of individual or collective selfdefence if an armed attack occurs against a Member of the United Nations, until the Security Council has taken measures necessary to maintain international peace and security. Measures taken by Members in the exercise of this right of self-defence shall be immediately reported to the Security Council and shall not in any way affect the authority and responsibility of the Security Council under the present Charter to take at any time such action as it deems necessary in order to maintain or restore international peace and security. $<$ http://legal.un.org/repertory/ art51.shtml>.

11 G. Wang, What "Flaws" In the PPWT? The way forward for arms control in outer space, Vienna 2017.

12 The United States reiterates its view that existing international legal obligations, as reflected in Article 2(4) of the United Nations Charter, prohibit the use of force or the threat CD/2129; Remarks of Richard H. Buenneke Senior Advisor, National Security Space Policy Office of Emerging Security Challenges Bureau of Arms Control, Verification and Compli- 
A further aspect of the current draft treaty is the so-called "Executive Committee" outlined in Article VI. This concept was mentioned in the 2008 draft, but the current draft treaty fleshes out some of the responsibilities of this committee to include operation and implementation of the treaty, addressing alleged violations of the treaty, developing procedures for sharing data and information analysis, and distribution of information collected pursuant to transparency and confidence-building measures. The responsibilities outlined for the Executive Committee fail to spell out the structure, responsibilities and financial obligations with specific detail if at all.

With regards to dispute resolution, the current draft treaty outlines a graduated methodology in Article VII. However, an important exclusion from the dispute resolution mechanism in Article VII is the Permanent Court of Arbitration's new Optional Rules for Arbitration of Disputes Relating to Outer Space Activities (the Rules). Any dispute involving an enacted PPWT would involve state parties with competing geopolitical interests and would likely revolve around the use of dual-use technology. The availability of the Rules to impartially arbitrate a dispute arising out of an enacted PPWT would be an obvious option as part of any dispute resolution mechanism in order to obtain an impartial resolution.

Aside from the specific concerns outlined, the current draft, not unlike the original, is unclear. China and Russia responded to concerns by other states about the vagueness of the original draft by stating that further detail could be fleshed out once states became a party to the treaty. This means that in order to flesh out the detail, a state will have to legally bind itself to the PPWT in its current form before it can read the fine print. The US observed that this might give Russia and China significant legal influence to back a state into a legal and political corner, all the while enhancing its soft-power base in the $\mathrm{UN}$ and, specifically, in the Conference of Disarmament (CD). ${ }^{13}$

The United States has clearly articulated the many flaws (errors) of this draft treaty, understanding unusual, even potentially threatening behavior, where a satellite is observed doing something that is contrary to what its owners claim it is intended to do, is of great concern to us. This is important because not only do these actions create uncertainty for other satellite operations, but they also create uncertainty concerning the intentions of the satellite's owners or operators. The US State Department has rejected the draft treaty. This was not a surprise to anyone in the international community and certainly was expected by both the PPWT's sponsors. ${ }^{14}$ Absent a drastic shift in US space policy, the future legitimacy of the PPWT is more than questionable, if not terminal.

ance U.S. Department of State Advanced Maui Optical and Space Surveillance Technologies AMOS Conference Wailea, Hawaii, September 14, 2018

$13<$ https://www.state.gov/t/avc/rls/285128.htm>.

14 J. Foust, U.S. Dismisses Space Weapons Treaty Proposal As "Fundamentally Flawed", "Space News", September 11, 2014. 


\section{Space Security}

There are three definitions of "security in Outer Space": the protection of the space infrastructure against natural and man-made threats or risks; ensuring the sustainability of space activities; and "Outer Space for Security" -the use of space systems for security and defense purposes. "Security from Outer Space" means the protection of human life and the Earth environment against natural threats and risks coming from space.

The space infrastructure can be described as a network of space-based and groundbased systems interconnected by communication channels and enabled by access to space capabilities. It includes: a space segment (all systems of the infrastructure located in orbit, namely satellites required for the conduct of operations and delivery of intended service), a ground segment (all systems of the infrastructure located on the surface of the Earth and necessary for the conduct of operations in space and delivery of data and signals), a user segment (sub-part of the ground segment and composed of complementary ground-based systems required for the delivery of full-fledged space services accessible by end-users) and a down-link and up-link interface between the space and ground segments (i.e. including users' equipment) and to operate the space system and receive its data. The uplink refers to signals transmitted from the ground to space and the downlink refers to signals received on the ground from space. ${ }^{15}$

In the 21st Century, while mentioning space, we should put attention on the three "c's"congested, contested and competitive as a scene for space law regulation implementation.

\section{Congested Space}

From the beginning of the Space Age and the first satellite launch, i.e. Sputnik-1 on the 4th of October 1957, the number of space debris exceeds the number of operational satellites. As such, space debris poses a threat to the Near-Earth environment on a Global scale $^{16}$. The first awareness of the problem came out in 1960s, based on the research activities undertaken in the US.

Currently, the total number of objects larger than $10 \mathrm{~cm}$ has exceeded more than 17000 objects and objecst between $1 \mathrm{~cm}$ and $10 \mathrm{~cm}$, approximately 500000 among which only about 1400 are active satellites. Those remnants of human activity around space encompass all the inactive, manmade objects, including the fragments that are orbiting Earth or re-entering the atmosphere. Most catalogued objects however originated from more

15 European Space Policy Institute Report, Vienna 2018; Security in Outer Space: Rising Stakes for Europe, Report 64

16 J. Robinson, M.P Schaefer, K. U. Schrögl, F. von der Dunk ed., The status and future evolution of Transparency and Confidence Building Measures, in: The prospects for Transparency and ConfidenceBuilding Measures in Space, ESPI Report 27, Vienna 2010. 
than 290 break-ups in orbit, mainly caused by the explosion, and from about 10 suspected collisions (of which four are confirmed between the catalogued objects). That debris creates a significant risk to Space infrastructure as the collision with debris larger than $1 \mathrm{~cm}$ could disable an operational satellite or could cause the break-up of a satellite or a rocket body. Moreover, the impact by the debris larger than about $10 \mathrm{~cm}$ can lead to a catastrophic break-up as complete destruction of a spacecraft and the generation of a debris cloud.

The two major contributions to the population of the fragments came from a Chinese Anti-Satellite test targeting the Feng Yun-1C Weather Satellite on 11 January 2007, which created more than 3400 tracked fragments, and the approximately 2300 tracked fragments created from the first-ever accidental collision between two satellites, Iridium-33 and Cosmos-2251 on 10 February 2009.

Many years of technical discussion and various exchanges are reflected in the leading body in the field of space debris, i.e. Inter-Agency Space Debris Coordination Committee (IADC), founded in 1993 by ESA, NASA, Japan Space Agency (JAXA) and Russian Space Agency (ROSCOSMOS) (complemented by the other space agencies later on). The significance of those issues has been recognized globally and some measures where applied as the nearly universal adoption of the Liability Convention ${ }^{17}$ IADC's Space Debris Mitigation Guidelines ${ }^{18}$ or some work being performed at the level of the Technical Subcommittee of the United Nations' Committee on the Peaceful Uses of Outer Space (UN COPUOS) since 1994. However, the standardization measures are required in order to achieve a common understanding of the required task leading to the transparent and comparable processes as works performed with ISOWD 24113 Space Debris Mitigation. ${ }^{19}$ Additionally in order to address the issues posed by the Space debris on spacecraft activities, UN COPUOS has taken the initiative to create a set of internationally agreed Guidelines for the long-term sustainability of outer space activities ${ }^{20}$.

The growing number of spacecraft deployed around the globe and the growing trend of their miniaturization significantly multiplies the risk of in-orbit collision. Due to that fact, the systematically growth caused the necessity to gather more precise information on the location of the Earth-orbiting objects. Moreover, all expert analyses highlight the risk collision which will increase significantly with the appearance of so-called 'megaconstellations' (hundreds to thousands of satellites). ${ }^{21}$

17 Convention on International Liability for Damage Caused by Space Objects of 1972.

18 Inter-Agency Space Debris Coordination Committee, Space Debris Mitigation Guidelines, 2002.

19 International Standard Organization, Space Systems - Space Debris Mitigation, ISO TC 20/SC 14, 2011.

20 United Nations, Guidelines for the long-term sustainability of outer space activities, A/AC.105/L.315, 2018.

21 J. Radtke, C. Kebschull, E. Stoll, Interactions of the space debris environment with mega constellations using the example of the One Web constellation, "Acta Astronautica" 2017, vol.131, pp. 55-58. 
This trend has been noticed worldwide and as such reflected as a global concern within the international fora.

\section{Contested Space}

Beside the space debris, there are other challenges contemporary space must face. Today's world is more and more dependent on space assets and in parallel there are more and more states able to perform hostile actions against space-related infrastructure (groundbased and space-based). ${ }^{22}$ These issues are both related to civil security and defense, of course. In the civil world, the fast-growing dependence on the usage of assets as Global Navigation Satellite Systems (GNSS such as GPS and Galileo) is easy visible. A lack of access to space-based systems or a disruption in the continuity of those services may significantly shake the economy of the states and their internal security. This is even more visible in the military domain where the recent wars in Afghanistan and earlier in Iraq revealed the universality of space assets in contemporary wars. Those wars were the first real space wars with a wide scope of space assets utilized. Modern space systems, like information gathering satellites, were vastly used on missions that contributed to the preparation, execution of assessing operations. A similar situation concerns other assets like the GNSS Guidance Munition and Satellite Communications.

However, other states like Russia and China recognize the dependence of NATO and the US on space assets ${ }^{23}$. Because of this dependence, they pursue developing counterspace capabilities like anti-satellite weapons, electronic warfare, cyber and jamming capabilities, laser disabling or rendezvous and proximity operations (RPO).

NATO and the national answer to the developing of counter-space activities by hostile states has imposed an urgent need to improve SSA capabilities ${ }^{24}$. In particular, the US signed the so-called 'SSA Data Sharing Agreement's and cooperated in military SSA exercises as the global sentinel.

22 A. A. Faiyetole, Potentialities of Space-based Systems for Monitoring Climate, Policies and Mitigation at Climate Policies and Mitigations of Climate Process Drivers, "The International Journal of Space Politics and Policy” 2018, vol. 14, no. 8, pp. 28-48, Global Counter space Capabilities: An Open Source Assessment, April 2018.

23 S. Paracha, Military dimensions of the Indian Space Programs, "The International Journal of Space Politics and Policy"2013, vol. 11, no. 3, pp. 156-186.

24 J. J. Klein, The influence of Technology on Space Strategy, "The International Journal of Space Politics and Policy" 2012, vol.10, no. 1, pp. 8-26. 


\section{Competitive Space}

At the beginning of the 21st century, the international community is witnessed the confluence of several powerful economic and policy forces in the global space sector ${ }^{25}$. Due to the financial constraints at the governmental level, the emergence of the emergence of new space markets and involvement of venture capital in the commercialization of space market are increasing rapidly. In the same time, technology dissemination and lowering of the barriers to entry are bringing new opportunities to the public space programs. Thus, introducing some new space actors to the fold.

Moreover, this change to commercial space is being performed within the world. These changes which are rapidly and vastly reshaping the global context, making the commercial space more complex and challenging. The five major global trends dominant to Horizon 2030 are:

a) globalization will continue moving towards more interdependence, but also fragmented governance and insecurity (specifically cyber- insecurity);

b) The revolution in technologies and their application will continue to transform societies in almost every aspect;

c) The nexus of climate change, energy and resources (including food security and water supply) will intensify;

d) The shift in the world economy towards Asia will continue;

e) Ageing will be global; Europe will be the "oldest" region; inequalities (in different forms, e.g. income, age, gender, digital divide) will persist; and migration may well further increase. ${ }^{26}$

In this environment the key driver of the Space change today is the enabling of major change in the commercial launch and satellite manufacturing industries. While relatively small markets today, rapidly falling costs are lowering the barrier to participate in the Space economy, making new industries like space tourism, asteroid mining, and on-orbit manufacturing viable, and growing existing flagship communications satellite services business while taking exploration deeper into space. Space is also becoming a military focal point as government pivot off Earth. ${ }^{27}$

25 C. Al-Ekabi, S. Feretti, Yearbook on Space Policy 2016 - Space for sustainable development, ESPI, Vienna, 2018, p. 1 and next

26 European Strategy and Policy Analysis System ESPAS, Global Trends to 2030: Can the EU meet the Challenges Ahead? 2015; World Economic Forum Global Risks Report, Geneva 2017.

27 Profiles in Innovation: Space: Next Investment Frontier, April 2017. 
110 | Adam Mickiewicz University Law Review

\section{Doctrine and Policy of Counter-space in Selected States}

\section{United States}

The U.S. SSA system is the most advanced in the world and relies on a national infrastructure called the U.S. Space Network (SSN), a network of 30 surveillance sensors including radars and optical telescopes, operated by military and civilian entities. Partial access to American SSA data is granted to select partners through a worldwide cooperation scheme. Today, the U.S. has more than 70 unclassified SSA Sharing Agreements with commercial and institutional organizations. These SSA Sharing Agreements aim to support transparency on operation in outer space, promote cooperation for security, enhance the availability of information among the partners, and improve the quality of U.S. SSA information. In practice, SSA Sharing Agreements provide selected organizations, which are not affiliated to the federal government, including foreign institution and private operators, with free access to authorized data stemming from SSN (U.S. Space Surveillance Network) sensors. ${ }^{28}$

Most recent U.S. presidential administrations have directed or authorized research and the development of counter-space capabilities, and in some cases green light testing or operational deployment of counter-space systems. These capabilities have typically been limited in scope, and designed to counter a specific military threat, rather than be used as a broad coercive or deterrent threat (for example, the most recent national space policy issued by the Obama Administration in 2010).

The link between these policy statements and offensive counter-space capabilities can be found in the official U. S. military doctrines on space operation. Two different doctrines exist on space operation: an Air Force doctrine developed by United States Air Force Space Command, and a joint doctrine developed by United States Strategic Command. The most recent publicly available versions of this doctrine are August 2018 and April 2018, respectively. Under current doctrine, the U.S. military considers counter-space operations to be a separate mission area of space operation. Counterspace operations consist of defensive space control (DSC) and Offensive Space Control (OSC), both of which are supported by SSA. DSC consists of active and passive actions to protect friendly space-related capabilities from enemy attack or interference by protecting, preserving, recovering, and reconstruction friendly-related capabilities before, during, and after an attack by an adversary. OSC consists of offensive operations to prevent an adversary's hostile use of U.S/ third- party space capabilities or temporary or permanently negate an adversary's space capabilities. Prevention can occur through diplomatic, informational, military, and economic measures, and negation can occur through active offensive and defense measures for deception, disruption, denial, degradation, or destruction. Ground- and space-based SSA capabilities are used to find, fix,

28 Security in Outer Space: Rising Stakes for Europe, Report 64, Vienna, August 2018, pp. 20-21. 
track, and target adversary space systems, and assess the effects of OSC operations. OSC actions may target space nodes, terrestrial nodes, and/or communications links.

It is still unclear whether the recent aggressive rhetoric from the Trump administration in the second half of 2018 and early 2019 is reflected in actual U.S. policy. In various speeches and statements promoting the Space Force, President Trump called for the U.S. to "dominate" space. Vice President Mike Pence reiterated this language in a speech at the Johnson Space Center, stating that the Trump Administration was taking steps to "ensure American national security is a dominance in space as it is here on Earth". In his remarks during the signing ceremony for establishing the Space Force, President Trump said the United States was developing, "a lot of new defensive weapons and offensive weapons" that they were now "going to the advantage of" the Space Force. Yet official U.S. policy statements on space security issues, or at least the public ones, continue to reflect a more moderate tone and do not explicitly outline the development of new offensive space weapons. ${ }^{29}$ President Trump provided peace through strength, stating that space is a warfighting domain and there is a need to "prioritize investments in resilience, reconstitution, and operations to assure [U.S.] space capabilities". ${ }^{30}$ There is a "whole-ofgovernment approach to U.S. leadership in space", in close partnership with the private sector and allies. 2018 Space Strategy included four essential pillars, all related to security \& defense: 1) Mission Assurance, 2) Deterrence and Warfighting, 3) Organizational Support, 4) Conducive domestic and international environment. In the US strategy, there is a need to assure military superiority in space and on the ground and strengthen deterrence in space and on the ground. Space infrastructure is a critical component of warfare. That is why there is a need for a reemergence of a space warfare doctrine and a need for tactical response options in space. There is a priority in safeguarding national security against space vulnerability and in the protection of critical space assets against threats (e.g. ASAT, cybersecurity, jamming \& spoofing). The US Strategy is fostering a commercial space, by giving way to a potentially promising commercial market and reinforcing global leadership in space. ${ }^{31}$

Civil space cooperation between the National Aeronautics and Space Administration (NASA) ${ }^{32}$ and Chinese organizations is restricted by the legislation in 2011. Despite the rhetoric of a space race between the United States and China, experts say there are opportunities for the US and China to expand cooperation in space that could have broader benefits. Brian Weeden, Director of Program Planning at the Secure World

29 Global Counterspace Capabilities: An Open Source Assessment, April 2019, pp.3.1-19. D. Werner, Controlling Space, "Aerospace", April 2019, pp. 22-28.

$30<$ https://www.federalregister.gov/documents/2018/06/21/2018-13521/national-space-trafficmanagement-policy>.

$31<$ https://www.federalregister.gov/documents/2018/06/21/2018-13521/national-space-trafficmanagement-policy>.

32 Hereinafter: NASA. 
Foundation said: "I absolutely agree that Wolf Admende does not prohibit cooperation, but the effect of it has been to prohibit it". There has been recent, if limited, cooperation between NASA and China on China`s lunar exploration program. ${ }^{33}$

\section{People's Republic of China}

Official Chinese public statements on space warfare have remained consistent: "China always adheres to the principle of the use of outer space for peace and opposes the weaponization of or arms race in outer space". However, since 2015, other official writing suggests China's position on space warfare and space weapons has become more nuanced. China`s 2015 defense White Paper, China`s Military Strategy, for the first-time designated outer space as a military domain and linked developments in the international security situation to defending China's interests in space. The defense White $\mathrm{Pa}$ per states that "outer space has become a commanding height in international strategic competition. States concerned are developing their space forces and instruments, and the first signs of weaponization of outer space, deal with security threats and challenges in that domain, and secure if space assets to serve its national economic and social development, and maintain outer space security." In particular, the White Paper states that "threats from such new security domains as outer space, and cyberspace will be dealt to maintain the common security of the world Community." In 2016, defense of China`s interests in space was made legally binding in China`s National Security Law.

The Chinese military does not appear to have an official doctrine governing space in military operations This may change in the coming years. On December 31st 2015, the Chinese military (the Strategic Support Force) intended, in part, to help to unify the command and control of Chinese forces and to make them more operationally responsive. More recently, U.S. intelligence officials state that the People`s Liberation Army (PLA) has "formed military units and begun initial operational training with counter-space capabilities that it has been developing, such as ground-launched ASAT missiles" toward the end of better integrating counter-space capabilities with other domains.

33 J. Foust, New opportunities emerging for U. S. - China space cooperation, in: 35th Space Symposium, Space News Show Daily, Sierra Nevada Corporation, 2019, p.14. J. Logsdon, There is no space race, “Aerospace" April 2019, pp. 46, 47. The U.S. Department of Defense has applied for \$304 million in funding to allow further research into space-based laser weapons, particle beams and other new forms of missile defense.

In 2023, U.S. Department of Defense employees want to test laser cannon in orbit to test different types of space-based weapons. A request has already been made for an additional $\$ 304$ million in the 2020 budget to develop stronger lasers and other next-generation missile defense tools. In 1967, the United States of America signed the Outer Space Treaty, which prohibits the placing of nuclear weapons in space. However, a member of the Department of Defense explained that the treaty does not constitute any obstacle to the deployment of lasers or particle beams in orbit, as the document only mentions 'weapons of mass destruction'. Pentagon wants to undertake the tests of space weapons. 
Nevertheless, Chinese thinking on space has remained consistent for at least the past two decades. According to the 2015 defense White Paper, the PLA will "endeavor to seize the strategic initiative in military struggle" and "proactively plan for military struggle in all directions and domains."

Chinese analysts argue that China must develop counter-space weapons to balance U.S. military superiority and protect China`s own interests. As one researcher writes, China`s development of ASAT weapons is to protect its own national security and adds that "only be prepared for war can you avoid war". The authors of the 2013 Science of Military Strategy write that given the wide range of rapid strike methods "especially space and cyber-attack and defense methods," China must prepare for an enemy to attack from all domains, including space. Chinese analysts write that having the ability to destroy or disable an opponent's satellites may deter an adversary from conducting counter-space operations against Chinese satellites. Space power can also improve the overall capabilities of the military and serve as a deterrent force not just against the use of specific types of weapons, but also as a general capability that can deter a state from even becoming involved in a conflict.

Chinese military writings state that the goal of space warfare and space operations is to achieve space superiority. Space superiority is defined as "ensuring one's ability to fully use space while at the same time limiting, weakening, and destroying an adversary`s space forces. It not only includes offensive and defensive operations in space against an adversary`s space forces, but also air, ground, and naval operations against space assets.

In recent years China has undertaken a significant reorganization of its military space and counter-space forces. Part of this reorganization included the creation of the Strategic Support Force (SSF) as the fifth military service by merging existing space, cyber and electronic warfare units under a new unified command that report directly to the Central Military Commission. The intent is to shift the PLA`s most strategic, informative mission from a discipline-centric to domain-centric force structure and enable fullspectrum war fighting. ${ }^{34}$

\section{The Russian Federation}

Before the collapse of the Soviet Union in 1991, marking the end of the first global space age, Russia was first in reaching several key space technology milestones. Although the Russian Federation achieved the greatest number of successful orbital launches of any state in 2014, Russia fell behind China and the United States in 2018 with only 19 launches to China`s 38 and the United States' 34. There is strong evidence that Russia has embarked on a set of programs over the last decade to regain some of its Cold War-era counter-space capability. Russia has a strong technical legacy to use. Under

34 Global Counterspace Capabilities: An Open Source Assessment, April 2019, pp.1, 1-22; China Space Threat Assessment, 2019, pp. 8-16. 
Putin, Russia also has a renewed political will to obtain counter-space capabilities for much the same reasons as China: to advance its regional power and limit the ability of the United States to impede Russia`s freedom of action. Unlike China, there is also significant evidence that Russia is actively employing counter-space capabilities in current military conflicts. There are multiple, credible reports of Russia's using jamming and other electronic warfare measures in the conflict in eastern Ukraine, and indications that these capabilities are tightly integrated into their military operations.

The Russian military sees the U.S. reliance on space-based assets as a vulnerability to be exploited. Russian thinking about conflict in space and space in conflict is much more a reflection of the evolution of modern warfare and the struggle to achieve information dominance during military operation. The Russian military is aggressively pursuing capabilities to degrade or destroy adversary space-based assets as well as to negate the advantage of space-based capabilities in theaters of conflict. Russian strategists see the trajectory of modern warfare being dominated by the struggle to achieve information dominance as a prerequisite to military victory. Space-based, informationdriven military capabilities make non-contact warfare possible, through such enabling actions as queuing and guidance of long-range strike assets. Russian security strategists believe the struggle of information dominance begins before conflict and, once a conflict has ensued, is used to dominate an opponent's decision making by either denying the adversary`s ability to utilize space-enabled information or by corrupting that information to mislead an adversary into making decisions contrary to military objectives.

Russian objectives in space, however, face significant challengers over the near term primarily from industry shortcomings. The Ukrainian conflict and the subsequent sanction placed on the Russian Federation brought to light several Russian industrial and technological deficiencies in its space program such as the hardening and miniaturization of electronics, despite these challenges Russian President Putin recently announced a number of initiatives suggesting that Russia intends to aggressively address its shortfalls in space. ${ }^{35}$

\section{The Islamic Republic of Iran}

Iran`s pursuit of space capabilities is a relatively recent development, and its efforts in space are often viewed as a thinly-veiled cover for its developing ballistic missile program. Iran has a relatively weak space industrial base, especially given the Iranian Space Agency`s close ties to the nation`s Ministry of Defense, and evidence suggests that a portion of Iran`s space technologies were adapted from Russia and North Korea counterparts. Iran has a nascent space program, building and launching small satellites that have limited capability. Technologically, it is unlikely Iran has the capacity or motivation

35 Global Counterspace Capabilities: An Open Source Assessment, April 2019, pp. 2-1, 2-22, 2-24; Space Threat Assessment..., pp. 17-24. 
to build on-orbit or direct-ascent anti-satellite capabilities at this point. Iran has not demonstrated any ability to build homing kinetic kill vehicles, and its ability to build nuclear weapons is currently constrained by the Joint Comprehensive Plan of Action. Iran has demonstrated the ability to persistently interfere with the broadcast of commercial satellite signals, although its capabilities to interfere with military signals are difficult to ascertain.

Iran is also developing space launch capabilities. It already possesses a proven space launch, the Safir rocket which has been used to place four small satellites into orbit. Iran is developing a more capable SLV known as the Simorgh, but it has experienced significant delays. Simorgh shares some design similarities with the North Korean Unha SLV and was meant to have been launched in 2010. In April 2016, the first known test of the Simorgh was reported by American Intelligence agencies as a "partial success". ${ }^{36}$

\section{The Democratic People`s Republic of Korea (North Korea)}

Like many spacefaring Nations, North Korea`s space capabilities are closely tied to ballistic missile development. The Unha 3 - the space launch vehicle used for North Korea`s only two successful orbital launches - likely used components from other missiles within the state's arsenal, including the medium-range Nodong and Scud-class ballistic missiles. There is little indication that North Korea is making substantial efforts to build or sustain a space industrial base, but its missile program is growing, and many believe that it is aided by technology from China, Iran and Pakistan.

In its official statements, North Korea has never mentioned the intention of anti-satellite operations, suggesting that there is no clear doctrine guiding Pyongyang`s thinking at this point. North Korea does not appear motivated to develop dedicated counter-space assets, though certain capabilities in their ballistic missile program might be eventually evolved for such a purpose. There are multiple ballistic missiles systems, including those in the intermediate range ballistic missile and ICBM (Intercontinental Ballistic Missile) class, which could possibly be used as the basis for future DA-ASAT capabilities. North Korea, has demonstrated the capability to jam civilian GPS signals within a limited geographical area. Their capability against U.S. military GPS signals is not known. There has been no demonstrated ability to interfere with satellite communications, although their technical capability remains unknown.

North Korea currently possess a basic satellite development and command and control capability, but they have not demonstrated any of the rendezvous and proximity operations and active guidance capabilities necessary for a co-orbital satellite capability. There are currently six objects in orbit as a result of two North Korean space launches. Two of these objects are satellites. ${ }^{37}$

36 Global..., pp. 4-1,4-2; 25-29.

37 Global..., pp, 5-1, 5-3; Space Threat Assessment..., pp. 30-34. 


\section{Situational Awareness (SSA) and Space Traffic}

All above trends in Space (i.e. increased number of space objects, militarization and commercialization $)^{38}$ make space a much busier place that must be appropriately reflected in effective SSA and its evolution to Space Traffic Management (STM). Additional supplementing of operational aspects as the Space Weather (SWE) and NEO (Near Earth Orbit) both enhance maturity and effectiveness of the SSA system and protection and security in space and on the ground.

Many states have increased spending devoted to data collection and processing; it is evident that for many of these states, SSA is a priority. For example, in 2017 Japan invested 1.7 billion USD ( $\$ 16 \mathrm{M}$ ) and requested 1.8 billion USD ( $\$ 17 \mathrm{M})$ in 2018 for SSA activities. Australia intends to spend $\$ 1 \mathrm{~B}$ to $\$ 2 \mathrm{~B}$ USD on SSA activities from 2018 until 2035. The EU SST (European Union Space Surveillance and Tracking) has committed $€ 70 \mathrm{M}(\$ 87 \mathrm{M})$ between 2015 and 2020 and is expected to invest more money after 2020. Some states have ground-based sensors that could be used for SSA but currently are not. Others do not currently have data collection capabilities but are interested in building sensors for part-time or dedicated SSA use. Similarly, some states may be thinking about repurposing existing sensors for part-time or dedicated SSA use. States and consortia with data collection capabilities are either keeping the data to use domestically or within their consortium or are actively sharing their data in some form with one or more states. On the commercial side, some vendors are either not participating in any data colection or are not operating sensors but pulling data from other sources. Other companies are planning or building sensors to operate, while others already operate sensor networks. States would prefer to mature and engage their own private organizations rather than international ones.

Some states are in the nascent phases of developing software. Others are developing their own software but rely heavily on the use of outside tools or services; others who are developing their own software capabilities are mostly autonomous but still use some outside tools and services. A couple of states in the matrix have been identified as having fully autonomous software capabilities. Commercial vendors fall in similar categories.

Some states have basic product abilities such as calculating launch and reentry trajectories. States and vendors able to deliver products beyond launch and reentry are considered as more mature. These states did not necessarily need to have a "comprehensive" list of SSA products to be considered mature. Instead, the groupings were based on the ability to develop products autonomously, similar to the groupings for SSA software. Private sector capabilities are increasing; based on their location in the space traffic system (collection, processing, and products). There is an assessment of what role the private

38 R.G. Harrison, Unpacking the Three C's: Congested, Competitive and Contested Space, "The International Journal of Space Politics and Policy", vol. 11, no. 3, pp.121-131. 
sector is playing in changing the structure of the SSA system. It important to note first, that the private sector has always been a significant part of the SSA enterprise.

What has changed however in recent years is that the SSA sector is beginning to undergo a functional modularization. The integrated "end-to-end" SSA process-data collection, processing, generation of SSA products and value added services- that was previously controlled by a large government military organization (e.g. the US Department of Defense) is being broken up into segments. This breakup is allowing more players, especially in the private sector that can sell piecemeal information, to enter the system, and there is a growing number of companies offering SSA data, software, and services.

A growing number of these companies are privately funded (though most likely serve government customers, at least for now). For example, spin-off LeoLabs in the United States is funded by several venture capital firms including Horizons Ventures, based in Hong Kong, and Airbus Ventures (Airbus's early-stage investment group). There is not much information on sources of funding for other firms, as most of them are either privately held (examples include companies such as AGI, Exo Analytics, Express SAR) or parts of larger conglomerates (such as Airbus). Private companies serve both private satellite owner/operators as well as governments globally. There are many organizations involved in data collection. Together, AGI and Exo-Analytic have well over 200 telescopes around the globe. France's Ariane Group similarly has global coverage of GEO. Some private organizations involved in SSA data processing have developed fully commercial catalogs using purely commercial, scientific, and international data. By some accounts, these databases provide better information than the DoD. Some companies (e.g., Airbus/Europe, SDA/multinational, and Space Nav/US) also provide additional data processing services to augment the DoD's conjunction warnings to satellite operators. As the preceding sections have indicated, the private sector, which includes not just commercial firms but also non-profits and academic institutions, is on track to match and exceed USG capabilities, at least what the U.S. releases publicly. Not only are many of these companies' capabilities comparable or better than the U.S. Government, they are cheaper as well.

The private sector is finding willing international customers leveraging commercial capabilities to grow indigenous capabilities. U.S.-based firms have both direct customers and resellers in a growing list of international customers. And the list of providers is growing. Some companies work under the umbrella of their governments (e.g. IHI in Japan). More "commercial-like" foreign companies (e.g., GMV) are, however, starting to develop.

As a result of the increasing number and improved performance of all SSA sensor types and software, the quality of SSA tracking for decision making will continue to improve. While optical sensors have become cheaper and more ubiquitous, radar technology remains expensive and mostly limited to governments. Other technologies such 
as ground-based and space-based radio frequency and laser ranging are rapidly improving and adapting for SSA applications. The expected increase of space-based sensors, optical and Radio Frequency will also have an impact on the overall quality of SSA tracking. Software is rapidly improving with respect to falling cost, growing timeliness, and increasing performance. In this section we discuss the implications of these trends.

Globally, states are increasing their investments in SSA capabilities. In a couple of instances, notably with Russia and China, investments in-house, reflect a desire to develop and maintain an SSA system independent of the U.S. SSA system. Their ability to process these data and use in-house software to develop SSA products, however, is not clear and is not likely as mature as that of the United States. China and Russia's interest to develop independent systems is likely strategic, and any improvements to the U.S. system, even increased transparency, is unlikely to dissuade states such as China and Russia from continuing to develop their own capabilities.

However, in other instances, such as in Europe, Japan, and elsewhere, the desire to develop in-house SSA capabilities reflects the desire to increase autonomy and be improved stakeholders. Thus, it is likely that states will continue developing their own independent capabilities regardless of whether the United States improves SSA products shared internationally. An analogy to this is GPS. After the United States developed GPS, and despite sharing its capabilities with the rest of the world, other GPS alternatives independently emerged: Galileo (EU), BeiDou (China), GLONASS (Russia), QZSS (Japan), IRNSS (India). ${ }^{39}$

\section{Final Remarks}

The types of space-to-space threats described above have distinctly different characteristics that make them suitable for different situations. A counter-space weapon that has been reversible, difficult to attribute and has limited social awareness is ideally suited to situations where the opponent may wish to signal or cause uncertainty in the opponent's mind without causing escalation. For example, without a credible assessment of combat damage, an opponent cannot act with confidence that his actions in space have been successful. In addition, weapons that cause additional damage in space, such as large quantities of space debris, risk escalating the conflict unintentionally and turning other nations against the attacker, , or may damage the attacker's own space systems. The described situation above is not covered by existing international space law which

39 B. Lal, A. Balakrishnan, B. M. Caldwell, R. S. Buenconseja, S. A. Carioscia, Global Trends in Space Situational Awareness (SSA) and Space Traffic and Management (STM), Virginia 2018, pp. 38-57; T. Masson-Zwaan, The international Framework for Space Activities, in: Handbook for New Actors in Space, ed. C.D. Johnson, Denver-Colorado 2017, pp.40,41. G. Gasparini, V. Miranda, Space situational awareness, in: The Fair and Responsible Use of Space: An International Perspective, ed. W. Rathgeber, K. U. Schrögl, R. A. Wiliamson, Wien-New York , 2010 , pp. 73-84 
is lacking in this regard. That is why it seems that the cooperation of states under the SSA system and sharing information among as many participants as possible is crucial in case to be aware of all situations which may happen in space not only to those states which are space powers, but also to others that are not. The SSA challenge may be to implement such a system on the national level. The system should be a part of strategy and should be properly implemented into national system of law.

\section{Literature}

A1-Ekabi C., Feretti S., Yearbook on Space Policy 2016 - Space for sustainable development, ESPI, Vienna, 2018, p. 1 and next

European Space Policy Institute Report, Vienna 2018;

Faiyetole A. A., Potentialities of Space-based Systems for Monitoring Climate, Policies and Mitigation at Climate Policies and Mitigations of Climate Process Drivers, "The International Journal of Space Politics and Policy" 2018, vol. 14, no. 8.

Foust J., New opportunities emerging for U. S. - China space cooperation, in: 35th Space Symposium, Space News Show Daily, Sierra Nevada Corporation, 2019.

Foust J., U.S. Dismisses Space Weapons Treaty Proposal As "Fundamentally Flawed" "Space News" September 11, 2014.

Gasparini G., Miranda V., Space situational awareness, in: ed. W. Rathgeber, K. U. Schrögl, R. A. Wiliamson The Fair and Responsible Use of Space: An International Perspective, Wien-New York , 2010.

Harrison K. Johnson, T. G. Roberts, M. Bergethon, A. Coultrup, Space Threat Assessment, 2019.

Harrison R. G., Unpacking the Three C's: Congested, Competitive and Contested Space, "The International Journal of Space Politics and Policy", vol. 11, no. 3.

Klein J. J., The influence of Technology on Space Strategy, "The International Journal of Space Politics and Policy" 2012, vol. 10, no. 1.

Lal B., Balakrishnan A., Caldwell B. M., Buenconseja R. S. , Carioscia S. A., Global Trends in Space Situational Awareness (SSA) and Space Traffic and Management (STM), Virginia 2018.

Logsdon J., There is no space race, "Aerospace” April 2019.

Masson-Zwaan T., The international Framework for Space Activities, in: Handbook for New Actors in Space, ed. C. D. Johnson, Denver-Colorado 2017.

Paracha S., Military dimensions of the Indian Space Programs, "The International Journal of Space Politics and Policy" 2013, vol.11, no. 3, pp. 156-186.

Radtke J., Kebschull C., Stoll E., Interactions of the space debris environment with mega constellations using the example of the One Web constellation, "Acta Astronautica"2017, vol.131. 
Robinson J., Schaefer M.P, Schrögl K. U., von der Dunk F. ed., The status and future evolution of Transparency and Confidence Building Measures, in: The prospects for Transparency and Confidence-Building Measures in Space, ESPI Report 27, Vienna 2010.

Wang G., What "Flaws" In the PPWT? The way forward for arms control in outer space, Vienna 2017.

Weeden B., Samson V. ed., Global Counterspace Capabilities: An Open Source Assessment, 2019.

Werner D., Controlling Space, “Aerospace”, April 2019, pp. 22-28.

$<$ http://legal.un.org/repertory/art51.shtml $>$.

$<$ https://www.federalregister.gov/documents/2018/06/21/2018-13521/national-spacetraffic-management-policy>.

$<$ https://www.federalregister.gov/documents/2018/06/21/2018-13521/national-spacetraffic-management-policy>.

$<$ www.unog.ch>.

SUMMARY

\section{Global Space Security and Counterspace Capabilities. Legal and Political Challenges}

This article undertakes a very sensitive issue: space security and counterspace capabilities and arms control. Those issues come under the sovereignty of each state and are strictly connected to national defense and policy. Counterspace, also known as space control, is the set of capabilities or techniques that are used to gain space superiority. Space superiority is the ability to use space for one`s own purposes while denying it to an adversary. These issues are so important now in the era of fast-growing state activities in space and under such a big dependence on space. Anti-satellite weapons (ASAT) are a subset of offensive counterspace capabilities, although the satellite itself is only one part of the system that can be attacked. That is the reason why protecting space infrastructure, in the absence of stabilized international space control cooperation and difficulties in reaching an agreement on PPWT treaty and lack of progress of international space law in this matter, is crucial by building the Space Situational Awareness system. Collaboration of states in this matter seems to be a priority.

Keywords: Space security, counterspace, space weapon, Space Situational Awareness.

MaŁgorzata Polkowska, War Studies University, Institute of Law, A. Chruściela „Montera” 103, 00-910 Warszawa, Republic of Poland, e-mail: m.polkowska@akademia.mil.pl. 